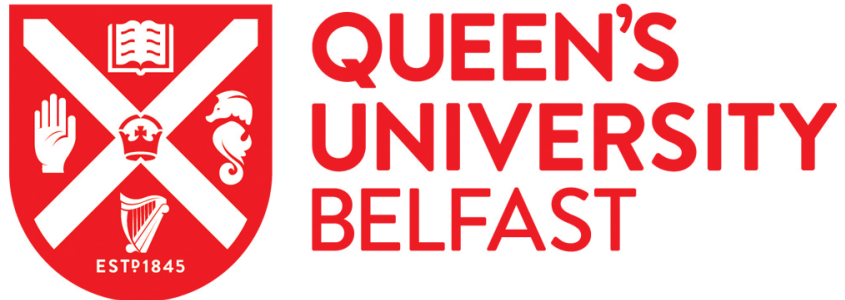

\section{Contest behaviour varies in relation to reproductive opportunities and reproductive success in the fallow deer}

Jennings, D. J. (2020). Contest behaviour varies in relation to reproductive opportunities and reproductive success in the fallow deer. Animal Behaviour, 163, 95-103. [19-00657R].

https://doi.org/10.1016/j.anbehav.2020.03.003

\section{Published in:}

Animal Behaviour

\section{Document Version:}

Peer reviewed version

Queen's University Belfast - Research Portal:

Link to publication record in Queen's University Belfast Research Portal

\section{Publisher rights}

Copyright 2020 Elsevier.

This manuscript is distributed under a Creative Commons Attribution-NonCommercial-NoDerivs License

(https://creativecommons.org/licenses/by-nc-nd/4.0/), which permits distribution and reproduction for non-commercial purposes, provided the author and source are cited.

\section{General rights}

Copyright for the publications made accessible via the Queen's University Belfast Research Portal is retained by the author(s) and / or other copyright owners and it is a condition of accessing these publications that users recognise and abide by the legal requirements associated with these rights.

Take down policy

The Research Portal is Queen's institutional repository that provides access to Queen's research output. Every effort has been made to ensure that content in the Research Portal does not infringe any person's rights, or applicable UK laws. If you discover content in the Research Portal that you believe breaches copyright or violates any law, please contact openaccess@qub.ac.uk. 
1

2

3

4

5

6

7

8

9 Correspondence: d.jennings@qub.ac.uk

10

11

12

13 fallow deer.

Dómhnall J. Jennings

School of Biological Sciences,

Queen's University Belfast, BT9 5DL 
Theory expects contestants to adjust their investment in fighting in line with the perceived value of a resource. Thus, we expect to see an increase in contest duration or aggressive actions if the subjective value of the resource is estimated to be high relative to occasions where the value is estimated to be low. Although well established in theory, we know little about how contestants structure their contests over resources in the wild, in particular, how variation in resource availability affects how contestants invest in fights. The objectives of this study were twofold: (i) to examine whether the structure of fights varied with presence and abundance of oestrous females in the population and, (ii) whether there was an association between investment in fighting and mating success during fallow deer (Dama dama) fights. Subordinate but not dominant contestants increased their rate of attacking actions when there were oestrous females in the population. However, there was no association between dominant or subordinate contest actions and variation in the number of oestrous females on any single day. With regard to mating success, dominant males that increased their attack rate during fights were more likely to achieve a mating than those that did not, although this investment in attacks was not associated with the number of matings obtained. Conversely, mating success was associated with a reduction in the number of parallel walks for subordinate contestants. Therefore, subordinate males achieved more matings when ritualized display behaviour was reduced or omitted from the contest. These results suggest that a desperado effect may be present, and that contestants use an estimate of resource value rather opponent quality when investing in contests.

Key words: Dominance, fighting, game theory, mating success, resource holding potential, resource value, ritualized displays 
Escalated aggressive encounters often occur between individuals as they attempt to secure access to scarce, non-divisible, and therefore, valuable resources. Whilst early models of contest behaviour assumed that individuals did not gather information during contests (e.g. Bishop, Cannings \& Smith, 1978; Hammerstein \& Parker 1982; Payne \& Pagel 1996; Payne 1998), accumulating evidence has shown that both opponent quality (Parker 1974) and resource value can play a fundamental role in influencing contestant behaviour during escalated contests (Arnott \& Elwood 2008; Hardy \& Briffa 2013 and chapters therein). To account for such findings, theory has sought to incorporate information gathering as a critical element of decision making during contests (e.g. Parker \& Rubenstein 1981; Enquist \& Leimar 1987; Enquist, Leimar, Ljungberg, Mallner \& Segerdahl, 1990).

One general approach towards understanding how resource value influences contestant motivation involves estimating the effect of resources such as food, territory site, shelter or mating opportunities on behaviour (see Table 1 in Arnott \& Elwood, 2008). But although the association between motivation and resource value is central to contest theory (Enquist \& Leimar, 1987), support for this relationship during fights has been mixed. For example, contestants with prior experience of the resource competed for longer than naïve contestants in the autumn spider (Metellina segmentata, Hack, Thompson \& Fernandes, 1997). Conversely, male sand gobies (Pomatoschistus minutus) did not adjust their display rates based on nest size in staged contests (Lindstrom, 1992), and the larvae of the net-spinning caddisfly (Arctopsyche ladogensis) do not fight for longer based on silk investment in retreats and catchnets (Englund \& Olsson, 1990). In terms of reproductive opportunity, male crickets (Acheta domesticus) will initiate and win more fights based on time since last mating, however, there is no relationship between signal rate and motivation to access females (Brown, Smith, Moskalik \& Gabriel, 2006). Furthermore, male shore crabs (Carcinus maenas) will fight for longer and with greater intensity when female pheromones are present (Sneddon, Huntingford, Taylor \& Clare, 2003). Nevertheless, although apparently contradictory, theory allows for such findings because contestants are expected to attempt to conceal their motivational state from their opponent (Maynard Smith \& Parker 1974). As a consequence, experimental approaches to studying contestant motivation often necessitate the use of indirect tests of contest motivation (e.g. Elwood, Wood, Gallagher \& Dick, 1998).

Theory also suggests that individuals adjust their effort in-line with an estimate of resource abundance. Nevertheless, despite the extensive literature concerning resource value and contestant behaviour, there is limited information available concerning whether individuals alter their motivation if the availability of the resource fluctuates over time. In a series of experimental studies investigating how resource distribution affects decision making, Noël, Grant \& Carrigan (2005, see 
also Grant, Girard, Breau \& Weir, 2002) showed that the number of chases between convict cichlids (Archocentrus nigrofasciatus) increased when the ratio between contestant density and defendable food patches increased from 1:1 to $2: 1$. However, as the ratio increased beyond two there was a significant decline in aggressive chases. This was presumably due to fewer encroachments by subordinates as a consequence of the declining payoff of food rewards available. Field studies have reported that contest actions are associated with the number of females in proximity to fallow deer males (Alvarez, 1993). As a percentage of the overall number of contest actions, attacking jump clashes increased whereas pushes and parallel walks decreased with increases in female density (Alvarez 1993, Table 6). Conversely, in harem holding red deer (Cervus elaphus), males fought for longer when most mating opportunities were available at the peak of the rut relative to the pre- and post-peak (Clutton-Brock, Albon, Gibson \& Guinness, 1979). The most parsimonious interpretation of this finding is that subordinate stags adjusted their investment in fighting relative to the abundance of oestrous females in the population (Taylor \& Elwood, 2003). Nevertheless, using a similar methodology, Jennings, Gammell, Carlin \& Hayden (2004) failed to show such re-adjustments of investment in a non-harem holding population of fallow deer.

Because individual quality is considered an important limiting factor for contest investment (Parker, 1974; Payne \& Pagel, 1996, 1997), it is possible that the status of the competitor during dyadic contests, as dominant or subordinate, is central to understanding contest behaviour when resource availability varies (Enquist \& Leimar, 1987). Since this potentially important distinction has not to my knowledge been addressed in previous studies, one aim of this study is to examine whether, and to what extent contestants adjust their tactical behaviour in response to a resource that fluctuates in abundance over time. In addition, theory also expects that individuals that are willing to fight harder or to persist for longer than their opponent should ultimately be victorious (Payne, 1998; Taylor \& Elwood, 2003; Briffa \& Elwood, 2009). For example, fallow deer attacking actions are associated with contest victory (Jennings, Gammell, Payne \& Hayden, 2005a), while hermit crabs that compete more vigorously are more likely to acquire their opponent's shell (e.g. Briffa, Elwood \& Dick, 1998, see also Hazlett, Rubenstein \& Ritschoff, 1975; Enquist, Plaine \& Roed, 1985). Therefore, a second objective of this study is to determine whether the behavioural tactics used by dominant and subordinate contestants are associated with mating success over the course of the annual fallow deer rut.

Male fallow deer show heightened levels of aggression just prior to and during the annual rut as they compete with each other for access to females (Apollonio, Festa-Bianchet, Mari, Mattioli \& Sarno, 1992; Moore, Kelly, Cahill \& Hayden, 1995; Fričová et al., 2007). But although the majority 
of males engage in elevated levels of aggression during the rut (Jennings et al. 2006), reproductive success is highly skewed and only a minority of males gain matings (Apollonio, Festa-Bianchet \& Mari, 1989; Festa-Bianchet et al., 1990; Moore et al., 1995). Although the contests of males are structurally complex, including vocalizations, visual displays and physical attacks (Alvarez, 1993; Bartoš et al., 2007; Fričová et al., 2007; Jennings, Gammell, Carlin \& Hayden, 2002, 2003, 2004, 2010; Jennings et al., 2005a; Jennings, Elwood, Carlin, Hayden \& Gammell, 2012) little is known about how males might adjust their investment in fights (i.e. vigour in the form of attacking actions and/or persistence as contest duration). In particular, how contest structure may change in relation to dayto-day variation in mating opportunities (but see Clutton-Brock et al., 1979; Alvarez, 1993; Jennings et al., 2004). This gap in our understanding of contest behaviour is addressed in this study. I ask two questions, the first, whether investment in fighting is associated with variation in daily mating opportunities and the second, whether this investment is associated with mating success.

In order to facilitate investigation of these questions I classed each fighter as either dominant or subordinate in that dyad on that day. There are theoretical reasons for taking this approach. One class of contest models predict that subordinates will reach their maximum investment in the contest first, whereas dominant individuals because of their greater current quality will not (Chapin, Peixoto \& Briffa, 2019). Accordingly, a relationship between contest dynamics and the ability of the subordinate to compete should be observed because weaker contestants determine contest duration (Taylor \& Elwood, 2003). Therefore, with respect to the first hypothesis that contest behaviour should be associated with resource abundance, I predict that there will be a positive relationship between subordinate behaviour and mating opportunities but no such association will be observed for dominant contestants. Moreover, if investment in fighting is key to gaining access to resources (e.g. Briffa et al., 1998), then a positive relationship should be observed for the contest behaviour of both (the dominant and subordinate) contestants and mating success. 
131 Study site and population: The study population was a herd of free-ranging European fallow deer

132 resident in Phoenix Park (Dublin, Ireland). The management plan for the herd involves locating and

133 tagging fawns with unique colour/numbered tags during June on an annual basis. As a consequence,

134 the majority of mature males in the population are identifiable by their ear tags; moreover, in

135 addition to ear tags, identification of individual males in the population is facilitated by a

136 combination of unique coat colour and antler conformation.

Ethics statement: The study was part of a long-term collaboration between University College Dublin and the authorities of the study site at Phoenix Park. It was conducted with the approval of the relevant Irish authorities (Dúchas, The Heritage Service of the Department of Arts, Heritage, Gaeltacht and the Islands and the Superintendent of Phoenix Park). As the study was observational, no specific licensing was required in order to conduct this study at the time.

The park is freely accessible to members of the public and located close to the city centre of Dublin; thus, the deer are habituated to the presence of humans, and tolerate their presence once they not directly approached. Observations of the herd were initiated at static distances from individuals and groups; thus, field workers did not approach within approximately 20/30 metres at the beginning of observation sessions, however, the deer were free to move closer over the course of a session. In so far as I can determine, the deer were unaffected by observer presence, and there were no environmental implications of the research.

\section{Data collection}

The annual rut in this population typically occurs during the last two weeks of October: matings were recorded as they occurred, including the identities of the male and female, the time and location. In the present study there were two dependent variables: (i) the number of oestrus females per day (i.e. mating opportunities for males), and (ii) the mating success of each male on any given day (i.e. the number of different females a male mated with that day).

Daily variation in the number of oestrous females in the population, and individual variation in mating success was examined in relation to four regressors estimated from fights recorded on video tape during October in 1996 and 1997. I extracted contest duration (time in seconds from initial contact of the antlers to last point of contact), number of parallel walks, and the rate of backward 
pushing and jump clashing (Alvarez, 1993; Jennings et al., 2003, 2005a) using the Observer video analysis system (Noldus Information Technology, Wageningen, The Netherlands). With respect to the latter two variables, it was possible to accurately assign jump clashes and backward pushes to the correct actor because both contestants were identifiable. Because backward pushes and jump clashes are dependent on antler contact, and thus contest duration, I calculated the action rate per minute (total number of actions/total time spent with antlers in contact*60: Jennings et al., 2005a) in order to normalise the data across fights.

Dominance ranking: In order to estimate dominance rank, all-event sampling was employed and data on aggressive behaviour was collected from late August to the end of the October (Altmann, 1974). Aggressive interactions between mature males were divided in two categories: noncontact interactions when opponents were displaced without physical contact being made, and fights where males physically engaged each other by locking antlers. When an interaction of either type occurred, the identity of the contestants, the time and date and outcome were also recorded (e.g. Jennings et al. 2006). Daily changes in rank were estimated from the outcome of the non-contact interactions only using the Elo-rating method (Elo, 1978); I estimated the rank of each male by calculating an initial Elo-rating from all decisively resolved interactions to the end of September, and then recalculated the Elo-rating for each day in October (Jennings, Boys \& Gammell, 2017, 2018). Using these ratings, a daily rank position was assigned to each male and this classified contestants as either dominant or subordinate members of their fighting dyad. I used this approach to categorising dyads because approximately half of the fights observed in this population end without any identifiable winner (Jennings, Gammell, Carlin \& Hayden, 2005b); therefore, classification on the basis of dyadic dominance relationship permitted the inclusion all contests that were recorded. Nevertheless, this approach can on occasion assign dominance to an individual that subsequently loses a fight. I screened the data and noted that such an outcome occurred in 32 fights analysed here (34\% of fights with a clear winner and loser; Dominant male won: Mean fight duration $=82.4$ seconds, $S D=80.6$; Dominant male lost: Mean duration $=82.4$ seconds, $S D=80.6)$. Because losers are thought key to controlling fight duration (and thus structure), I compared fights where the dominant won or lost. There was no difference in duration $(t=0.011, p=.99)$ indicating that there was no systematic bias in the analyses reported below based on the classification approach taken here. 
I ran three models to investigate the two hypotheses outlined above. The first model addressed the association between abundance of oestrous females in the population (DV) and contest behaviour of both dominant and subordinate males (IV). I included two random intercepts relating to the identity of the dominant and subordinate males (Briffa \& Elwood, 2010). The second and third models addressed the association between the mating success (DV) of the dominant male (model 2), the subordinate male (model 3) and it's contest behaviour (IV) with identity included as a random intercept Contest behaviour comprised of four different regressors described above: the rate of backward pushes and jump clashes per minute of the dominant and subordinate males, the number of parallel walks and contest duration in seconds. These data were log transformed and centred prior to analyses (Kruschke, 2015).

207

The statistical approach adopted here used Bayesian methods with a posterior distribution generated by MCMC and sampled using MCMCgImm (version 2.26: Hadfield, 2010). Within MCMCgImm, I analysed the data using a Zero-Altered Poisson model (ZAP, see supplementary materials for model codes and data files). The model performs a hierarchical regression at two levels: (i) a lower level where a binary regression is computed on the data, and (ii) an upper level model where a truncated Poisson model is run. To examine the first hypothesis, the lower level of the model estimated if there was an association between contest dynamics based on whether oestrous females were absent (pre-rut) or present (the rut) in the population. The upper level of the model examined the relationship between contest dynamics and the abundance of oestrous females on that day in the rut. The second hypothesis examined the relationship between mating success and fights that were recorded during the rut. I eliminated pre-rut fights because zero would have had two meanings at the lower level of the model (Blasco-Moreno, Pérez-Casany, Puig, Morante \& Castells, 2019). Specifically, that no matings were achieved by any male because there were no oestrous females in the population (pre-rut), or that the male failed to achieve a mating on any given day although there were mating opportunities in the herd (rut). Thus, the lower binary level of the model tested the relationship between contest dynamics and whether the contestant achieved a mating or not, while the upper level examined contest dynamics in relation to the number of matings achieved.

Each model was run over three independent chains with dispersed initial values, however, the adaptive phases of each model, the length of the posterior, and thinning intervals differed. For the model investigating resource abundance (hypothesis 1), an adaptive phase of 100,000 iterations 
including burn-in was employed, following which a posterior phase of 75 million iterations was run with a thinning interval of 1,000 to reduce autocorrelation (Jennings et al., 2017, 2018). The two models investigating mating success of the dominant and subordinate competitors, had an adaptive phase of 10,000 iterations and a thinning interval of 100 to reduce autocorrelation. The posterior phases of the two models were of different length: the model addressing mating success of the dominant males was run for 50 million iterations while the model addressing mating success of the subordinate contestant was run for 150 million iterations. I used a weakly prior for the regression coefficients and random effects, and tested for convergence of the posterior chains using the GelmanRubin statistic (Gelman \& Rubin 1992); a convergence level of $<1.1$ for each model parameter indicated that the adaptive phase of the model was sufficient (Kruschke, 2015).

In order to interpret the model output and determine the contribution of each parameter, I used the posterior means and the $95 \%$ credible intervals (Jennings et al. 2017, 2018). If the 95\% interval did not cover zero I concluded that the parameter was a meaningful predictor of the outcome variable. However, if the posterior mean value for a regressor coefficient fell below .02 I considered that there was no meaningful biological effect (Bridger, Bonner \& Briffa, 2015). In this study, as is usual in studies of contest behaviour the fight was treated as the experimental unit (Briffa \& Elwood, 2010); nevertheless, because I used dominant and subordinate as my criteria to categorise individuals within fights, there were occasions when an individual was dominant to his opponent in one fight, and subordinate to an opponent in a different fight. I estimated the correlation between the effect of individuals when dominant versus subordinate in the posterior chain of the random effects: the co-efficients indicated that there were very weak relationships at both levels of the model (Lower level: $r=0.37$ with dominant and $r=0.23$ with subordinate individuals; Upper level: $r=-0.13$ with dominant and $r=-0.19$ with subordinate individuals).

I examined the correlation coefficients between the four contest variables to test for collinearity between the posterior chains of the three models. For the model examining the relationship between resource abundance and contest behaviour the coefficients indicated that the posterior chains were weakly correlated at both the lower and upper levels of the model. The strongest correlations were observed between fight duration and the number of parallel walks at both levels (Lower level: $r=-0.45$; Upper level: $r=-0.46$ ). For the model examining mating success and the contest behaviour of the dominant contestant the strongest correlations between the posterior distributions were negative at both levels of the model (Duration and rate of backward pushing at the lower level: $r=-0.39$ and duration and rate of jump clashing at the upper level: $r=-0.48)$. For the model examining the relationship between the mating success and contest behaviour of the 
263 subordinate males the relationship between the posterior distributions of the four co-efficients

264 showed negative relationships at both levels of the model: the strongest relationships at the lower

265 level $(r=-0.39)$ and upper level $(r=-0.56)$ were between duration and rate of jump clashing.

266 Additional analysis using a generalised linear mixed modelling approach (GLMM) examined aspects

267 of the data in more detail using the R statistical package running Imer4 (version 1.1-21) and Imer test 268 (version 3.1-0). 
Resource abundance and contest dynamics

272

The lower level of the model indicated that there was no association between the presence of oestrous females and fight duration or the number of parallel walks that opponents engaged in. Furthermore, the presence of oestrous females was not related to an increase in attacking actions, either backward pushes or jumping clashes, by dominant males during fights. However, this was not the case for subordinate males. There was an increase in backward pushes and jump clashes when oestrous females were present in the population (see Figure 1a and Figure 2a,b). Therefore, as females in the population entered oestrous, subordinate contestants increased their aggression levels during fights whereas dominant males did not. At the upper level of the model there was no evidence for an association between the contest behaviour of either contestants in relation to the number of oestrus females on any given day (Figure 1b). Therefore, while the presence of oestrous females was associated with an increase in attacking actions by subordinate males, the abundance of mating opportunities in the population was not associated with contest behaviour.

Insert figures 1 and 2 here

Mating success and contest behaviour

(i) Dominant males: The rate of backward pushing during contests was positively related to whether dominant males mated on any particular day during the rut (Figure 3a). Thus, as the dominant contestant increased his effort at displacing his opponent there was an increased likelihood that he would achieve at least one mating (Figure 4). No other contest variable (contest duration, number of parallel walks, rate of jump clashing) showed a meaningful association with mating success. At the upper level of the model, 
(ii) Subordinate males: At the lower level of the model, there was no evidence that contest behaviour was associated with the probability that a subordinate male would achieve a mating (Figure 5a). At the upper level of the model, however, there was a negative association between the number of parallel walks and the mating success of subordinate contestants (Figure $5 b$ and Figure 6). Therefore, the number of matings subordinates gained on any particular day was associated with a reduction in opportunities for males to assess the quality of their opponent. Given that parallel walks could facilitate information gathering about opponent quality, this result suggests that weaker individuals can benefit when opportunities for assessment of resource holding potential is minimised. To further investigate this possibility, I examined the relationship between parallel walking (DV) and the difference in Elo scores on the day that opponents fought (IV) as an estimate of disparity in RHP. A generalised linear mixed model with subordinate identity entered as a random intercept showed that there was no association between the two factors $(z=0.52, p=.6, S E=0.06)$. 
318 Understanding the relationship between contest dynamics and resource availability is central to the development and refinement of models of contest behaviour. One general prediction of these models is that contest costs should increase in line with the value of the resource under dispute (Hammerstein \& Parker, 1982; Enquist \& Leimar, 1987). However, a number of studies have questioned this assumption and shown that individuals do not necessarily increase their effort if a valuable resource is at stake (e.g. Thornhill, 1984; Lindstrom, 1982; Jennings et al., 2003). This study indicates that in fallow deer it is the role of the contestant that is important; specifically, that subordinate (but not dominant) males increase their rate of attacking during contests when oestrous females are present in the population. A second hypothesis investigated whether there was an association between investment in fighting and mating success (Parker \& Rubenstein 1981). This prediction has been supported across a number of different contexts and species; for example, hunger (e.g. Rodriguez-Girones, Drummond \& Kacelnik, 1996; Nosil, 2002), and mating opportunities (Brown et al. 2006) are associated with contest success. With respect to mating success this study shows that a dominant males' investment in attacking actions was positively associated with whether it achieved a mating or not. For subordinate males the number of matings achieved was negatively associated with the number of parallel walks during contests.

The interaction between contestant behaviour and resource value is complex; it may depend on the ability of the contestants to gather information about the resource, the internal motivational state of the contestant, and/or the number of resources under dispute (see Arnott \& Elwood, 2008, Table 1). Moreover, as Arnott and Elwood (2008) have noted, studies addressing contest dynamics and resource value tend to neglect a fundamental question concerning whether contestants can perceive differences (as opposed to presence/absence) in the quality or quantity of the resource (e.g. Wells, 1988; Jackson, Walker, Pollard \& Cross, 2006). The majority of matings in this population occur as males interact with groups of females dispersed over their day range rather than from resource defence (i.e. a territory or harem, Moore et al., 1995) suggesting that males do not establish prior ownership. Thus, while males should be able to detect the presence of oestrous

344 females, they might be constrained when it comes to estimating how many are in the population.

345 Nevertheless, there are reasons to suppose that males may make some sort of estimate of the number females in oestrous. For example, the number of fights occurring on any day tends to

347 increase roughly in line with the number of matings recorded in several different deer populations 348 (e.g. Clutton-Brock et al., 1979; Clutton-Brock, Green, Hiraiwa-Hasegage \& Albon, 1988; Apollonio et al., 1992). Moreover, red deer stags fight for longer when competing for females during the 12-day 
period of peak conception compared to other time-periods (Clutton-Brock et al., 1979). I investigated these possibilities using a hierarchical approach to the data, and included a number of different contest parameters from each fight: fight duration, parallel walking and the offensive attacking actions employed by fighting males (Alvarez, 1993). The present study was unable to show that contest dynamics were related to the day-to-day variation in the number of oestrous females in the population. Moreover, this was the case regardless of whether the contestant was dominant or subordinate.

Contest theory expects that contest behaviour is linked with the resource holding potential of the competitors (Parker, 1974), and that the costs borne by an individual should be related to the value that an individual attaches to that resource. In the present study, we should expect that dominant individuals, as the superior quality contestant, will not reach their maximum investment before the subordinate (Taylor \& Elwood, 2003). Subordinate dyad members should therefore determine when an interaction ends as they will reach their maximum investment level first (e.g. Mesterton-Gibbons, Marden \& Dugatkin, 1996; Payne \& Pagel, 1996; 1997; Payne, 1998). There was no evidence to support the argument that subordinates altered their decision on when to terminate a fight. However, contest duration, as a proxy measure for cost, has been called into question (e.g. McGinley, Prenter \& Taylor, 2015); the present study supports the argument that putative measures of cost need to be carefully vetted. Nevertheless, subordinate males increased their attacking actions when the rut started which is consistent with an increase in motivation related to resource availability whereas dominant contestants failed to show a corresponding increase in attacking actions. This pattern of results is consistent with the prediction forwarded above. Moreover, these results suggest a 'desperado' effect is in operation in this population (Grafen, 1987); specifically, the idea that subordinate contestants should disregard asymmetries in RHP by investing in fighting if they place a high enough value on the resource being contested.

Models of contest behaviour focus on fight dynamics as a means of understanding the underlying decision processes used by contestants during fights (e.g. Enquist \& Leimar, 1987; Payne \& Pagel, 1996, 1997; Payne, 1998). In addition, we expect that the victor will outcompete its opponent and assume ownership of the resource (Riechert, 1998). The results of this study show that there was a positive relationship between the mating success of dominant males and the use of increased attacks on their opponent at the lower binary level of the model. Despite this association not being evident at the upper level it is consistent with theory. Surprisingly, this result contrasts with findings from population of fallow deer that adopt a similar mating strategy as this population (Alvarez, 1993). The study of Alvarez showed that as the local density in the number of females 
increased that there was a decline in pushing attacks during fights. The difference in results reported may be due to the methodologies adopted; I focussed on rate of actions with identified males of known dominance and mating success in comparison to actions as a proportion of the total actions per contest between males of unknown dominance status and using local doe presence rather than mating success.

The behaviour of subordinates was associated with mating success. Although there was no relationship between behaviour and achieving a mating at the lower level of the model, there was a meaningful effect at the upper level: a negative association between the number of parallel walks per fight and mating success. Therefore, an absence of parallel walking was associated with increased matings for weaker contestants. Certain models of contest behaviour focus on the evolution of low cost display behaviour as a means of reducing the probability of serious injury through fighting with stronger opponents (e.g. Enquist \& Leimar, 1983). One such display is the parallel walk which is presumed to function as a means through which fighting males can assess the resource holding potential of their opponent (e.g. Clutton-Brock \& Albon, 1979; Jennings et al., 2003). Consistent with such an argument there is evidence that parallel walking is associated with high levels of individual visual lateralisation (Jennings, 2012). Conversely, contestants may eschew the inclusion of ritualised displays in favour of a more risky tactical approach uncorrelated with the resource holding potential of the contestants (e.g. Draud, Macías-Ordóñez, Verga \& Itzkowitz, 2004; Fowler-Finn \& Hebets, 2006; Arnott \& Elwood, 2009). It has been argued that resource potential valuation (RPV) rather than RHP might drive decision making during contests (Draud et al., 2004; Elias, Botero, Andrade, Mason \& Kasumovic, 2010). Given the negative association between matings achieved and numbers of parallel walks observed here, it could be that contest behaviour is influenced by RPV, rather than RHP.

In order to examine this possibility I examined whether the difference in dominance rank between the contestants on a particular day, was associated with the number of parallel walks. It has been shown elsewhere that RHP (body weight and neck girth) is associated with dominance rank (Jennings et al., 2010), and that fight losers tend to initiate parallel walking (Jennings et al., 2003). Therefore, if contestants are employing an assessment process based on RHP, we should observe a negative association between difference in rank and number of parallel walks. This was not the case. Given the high skew in reproductive success in this population most males will not achieve any matings (Moore et al., 1995); thus, ritualised displays may provide little incentive to weaker opponents as they gain little from them (Enquist \& Leimar, 1990). Therefore, expected reproductive success may be an important variable in male-male contests where mating success is concentrated 
among a minority of competitors. Since subordinate contestants are highly likely to initiate parallel walks (Jennings et al., 2004), the question as to why subordinates use these ritualised displays on some occasions, whilst not on others, will require further investigation.

Studies conducted in natural settings into how contest structure and resource availability covary over time are rare, and I am not aware of any that have investigated contest structure from the perspective of the dominant and subordinate contestants. However, changes in rank during the rut, the permanency of any rank change, encounter rates with opponents and/or the cost of fighting might play an important role (see Elias et al., 2010 for a related discussion). The present study was conducted to test ideas central to contest theory concerning contestant behaviour and resource value and mating success. In order to do so I examined the behaviour of dominant and subordinate fighters as they competed over a temporally extended period (four weeks approximately) during the pre-rut and the rut. Consistent with theory, I show that subordinate contestants increase their use of attacking actions when the rut begins whereas dominant fighters do not. Moreover, I show that an increase in the rate at which dominant males attack their opponent is associated with achieving a mating. Conversely, subordinate contestants' mating success was associated with a decline in parallel walking. What is evident here is that an emphasis on 'fighting harder' is perhaps too simplistic an argument to account for mating success: this study shows that the relationship between contest tactics and mating success is dependent on the role each contestant plays. While dominant individuals do increase their investment, subordinates do not. This suggests that subordinate males do not use estimates of RHP asymmetry to inform the decision of how to structure contests, rather an estimate of resource value is potentially the key variable. Theory argues that ritualised displays evolve to reduce the potential for serious injury. Further investigation of the conditions under which individuals omit the use of displays is needed given the significant payoffs associated with their absence as shown here.

Acknowledgements:

442 I would like to extend thanks to my colleagues at the Mammal Research Group at University College

443 Dublin for their help in the field. I would also like to thank Jarrod Hadfield for advice with

444 MCMCGImm and Loretta Troni for useful discussion of the text. I would also like to express my 445 thanks to the two anonymous referees for their constructive comments on a previous version of this 446 paper. 
Altmann, J. (1974). Observational study of behavior: sampling methods. Behaviour, 49, 227-267.

Alvarez, F. (1993). Risks of fighting in relation to age and territory holding in fallow deer. Canadian Journal of Zoology, 71, 376-383.

Apollonio, M., Festa-bianchet, M. \& Mari, F. (1989). Correlates of copulatory success in a fallow deer lek. Behavioral Ecology and Sociobiology, 25, 89-97.

Apollonio, M., Festa-Bianchet, M., Mari, F., Mattioli, S. \& Sarno, B. (1992). To lek or not to lek: mating strategies of male fallow deer. Behavioral Ecology, 3, 25-31.

Apollonio, M., Scotti, M. \& Gosling, L.M. (2003). Mating success and fidelity to territories in a fallow deer lek: a female removal experiment. Naturwissenschaften, 90, 553-557.

Arnott, G. \& Elwood, R.W. (2008). Information gathering and decision making about resource value in animal contests. Animal Behaviour, 76, 529-542.

Arnott, G. \& Elwood, R.W. (2009). Gender differences in aggressive behaviour in convict cichlids. Animal Behaviour, 78, 1221-1227.

Bartoš, L., Fričová, B., Bartošová, J., Panamá, J., Šustr, P. \& Šmídová, E. (2007). Estimation of the probability of fighting in fallow deer (Dama dama) during the rut. Aggressive Behavior, 33, 7 13.

Bishop, D.T., Cannings, C. \& Smith, J.M. (1978). War of attrition with random rewards. Journal of Theoretical Biology, 74, 377-388.

Blasco-Moreno, A., Pérez-Casany, M., Puig, P., Morante, M. \& Castells, E. (2019). What does a zero mean? Understanding false, random and structural zeros in ecology. Methods in Ecology and Evolution, 10, 949-959.

Bridger, D., Bonner, S.J. \& Briffa, M. (2015). Individual quality and personality: bolder males are less fecund in the hermit crab Pagurus bernhardus. Proceedings of the Royal Society, B, 282, 20142492.

Briffa, M. \& Elwood, R.W. (2009). Difficulties remain in distinguishing between mutual and selfassessment in animal contests. Animal Behaviour, 77, 759-762.

Briffa, M. \& Elwood, R.W. (2010). Repeated measures analysis of contests and other dyadic interactions: problems of semantics, not statistical validity. Animal Behaviour, 80, 583-588. 
Briffa, M., Elwood, R.W. \& Dick, J.T.A. (1998). Analysis of repeated signals during shell fights in the hermit crab Pagurus bernhardus. Proceedings of the Royal Society, B, 265, 1467-1474.

Brown, W.D., Smith, A.T., Moskalik, B. \& Gabriel, J. (2006). Aggressive contests in house crickets: size, motivation and the information content of aggressive songs. Animal Behaviour, 72, 225253.

Chapin, K.J., Peixoto, P.E.C. \& Briffa, M. (2019). Further mismeasures of animal contests: a new framework for assessment strategies. Behavioral Ecology, 30, 1177-1185.

Clutton-Brock, T.H. \& Albon, S.D. (1979). The roaring of red deer and the evolution of honest advertisement. Behaviour, 69, 145-170.

Clutton-Brock, T.H., Albon, S.D., Gibson, R.M. \& Guinness, F.E. (1979). The logical stag: adaptive aspects of fighting in red deer (Cervus elaphus L.). Animal Behaviour, 27, 211-225.

Clutton-Brock, T.H., Green, D., Hiraiwa-Hasegawa, M. \& Albon, S.D. (1988). Passing the buck: resource defence, lek breeding and mate choice in fallow deer. Behavioral Ecology and Sociobiology, 23, 281-296.

Draud, M., Macías-Ordóñez, R., Verga, J. \& Itzkowitz, M. (2004). Female and male Texas cichlids (Herichthys cyanoguttatum) do not fight by the same rules. Behavioral Ecology, 15, 102-108.

Elias, D.O., Botero, C.A., Andrade, M.C.B., Mason, A.C. \& Kasumovic, M.M. (2010). High resource valuation fuels "desperado" fighting tactics in female jumping spiders. Behavioral Ecology, 21, 868-875.

Elo, A.E. (1978). The Rating of Chess Players, Past, present and Future. New York: Arco.

Elwood, R.W., Wood, K.E., Gallagher, M.B. \& Dick, J.T.A. (1998). Probing motivational state during agonistic encounters in animals. Nature, 393, 66-68.

Englund, G. \& Olsson, T.I. (1990). Fighting and assessment in the net-spinning caddis larva Arctopsyche ladogensis: a test of the sequential assessment game. Animal Behaviour, 39, 5562.

Enquist, M. \& Leimar, O. (1983). Evolution of fighting behaviour: decision rules and assessment of relative strength. Journal of Theoretical Biology, 102, 387-410.

Enquist, M., Plaine, E. \& Roed, J. (1985). Aggressive communication in fulmars (Fulmarus glacialis) competing for food. Animal Behaviour, 33, 1007-1020. 
Enquist, M. \& Leimar, O. (1987). Evolution of fighting behaviour: the effect of variation in resource value. Journal of Theoretical Biology, 127, 187-205.

Enquist, M. \& Leimar, O. (1990). The evolution of fatal fighting. Animal Behaviour, 39, 1-9.

Enquist, M. \& Leimar, O., Ljungberg, T., Mallner, Y. \& Segerdahl, N. (1990). A test of the sequential assessment game: fighting in the cichlid fish Nannacara anomala. Animal Behaviour, 40, 1-14.

Festa-Bianchet, M., Apollonio, M., Mari, F. \& Rasola, G. (1990). Aggression among lekking male fallow deer (Dama dama): territory effects and the relationship with copulatory success. Ethology, 85, 236-246.

Fowler-Finn, K.D. \& Hebets, E.A. (2006). An examination of agonistic interactions in the whip spider Phrynus marginemaculatus (Arachnida, Amblypygi). Journal of Arachnology, 34, 62-76.

Fričová, B., Bartoš, L., Bartošová, J., Panamá, J., Šustr, P. \& Jozífková (2007). Females presence and males agonistic encounters in fallow deer, Dama dama during the rut. Folia Zoologica, 56, $253-262$

Gelman, A. \& Rubin, D.B. (1992). Inference from iterative simulation using multiple sequences. Statistical Science, 7, 457-511.

Grafen, A. (1987). The logic of divisively asymmetric contests: respect for ownership and the desperado effect. Animal Behaviour, 35, 462-467.

Grant, J.W.A., Girard, I.L., Breau, C. \& Weir, L.K. (2002). Influence of food abundance on competitive aggression in juvenile convict cichlids. Animal Behaviour, 63, 323-330.

Hack, M.A., Thompson, D.J. \& Fernandes, D.M. (1997). Fighting in males of the autumn spider, Metellina segmentata: effects of relative body size, prior residency and female value on contest outcome and duration. Ethology, 103, 488-498.

Hadfield, J.D. (2010). MCMC methods for multi-response generalized linear mixed models: the MCMCgImm package. Journal of Statistical Computing, 33, 1-22.

Hammerstein, P. \& Parker, G.A. (1982). The asymmetric war of attrition. Journal of Theoretical Biology, 96, 647-682.

Hardy, I.C.W. \& Briffa, M. (2013). Animal Contests. Cambridge: Cambridge University Press. 
Hazlett, B.A., Rubenstein, D.I. \& Ritschoff, D. (1975). Starvation, aggression, and energy reserves in the crayfish Orconectes virillis. Crustaceana, 8, 11-28.

Jackson, R.R., Walker, M.W., Pollard, S.D. \& Cross, F.R. (2006). Influence of seeing in a female on the male-male interactions of a jumping spider, Hypoblemum albovittatum. Journal of Ethology, 24, 231-238.

Jennings, D. J., Boys, R. J., \& Gammell, M. P. (2017). Investigating variation in third-party intervention behaviour during a fallow deer (Dama dama) rut. Behavioral Ecology, 28, 288-293.

Jennings, D. J., Gammell, M. P., Carlin, C. M. \& Hayden, T. J. (2002). Does lateral presentation of the palmate antlers during fights by fallow deer (Dama dama) signify dominance or submission? Ethology, 108, 389-401.

Jennings, D. J., Gammell, M. P., Carlin, C. M. \& Hayden, T. J. (2003). Is the parallel walk between competing male fallow deer, Dama dama, a lateral display of quality? Animal Behaviour, 65, 1005-1012.

Jennings, D. J., Gammell, M. P., Carlin, C. M. \& Hayden, T. J. (2004). Effect of body weight, antler length, resource value and experience on fight duration and intensity in fallow deer. Animal Behaviour, 68, 213-221.

Jennings, D. J., Gammell, M. P., Carlin, C. M. \& Hayden, T. J. (2010). Investment in fighting in relation to body condition, age and dominance rank in the male fallow deer, Dama dama. Animal Behaviour, 79, 1293-1300.

Jennings, D. J., Gammell, M. P., Carlin, C. M. \& Hayden, T. J. (2005b). Win, lose or draw: a comparison of fight structure based on fight conclusion in the fallow deer. Behaviour, 142, 423-439.

Jennings, D. J., Gammell, M. P., Payne, R. J. H. \& Hayden, T. J. (2005a). An investigation of assessment games during fallow deer fights. Ethology, 111, 511-525.

Jennings, D.J. (2012). Right-sided bias in fallow deer terminating parallel walks: evidence for lateralization during a lateral display. Animal Behaviour, 83, 1427-1432.

Jennings, D.J., Boys, R.J. \& Gammell, M.P. (2018). Suffering third-party intervention during fighting is associated with reduced mating success in the fallow deer. Animal Behaviour, 139, 1-8.

Jennings, D.J., Elwood, R.W., Carlin, C.M., Hayden, T.J., Gammell, M.P. (2012). Vocal rate as an assessment process during fallow deer contests. Behavioural Processes, 91, 152-158. 
Jennings, D.J., Gammell, M.P., Carlin, C.M. \& Hayden, T.J. (2006). Is difference in body weight, antler length, age or dominance rank related to the number of fights between fallow deer (Dama dama). Ethology, 112, 258-269.

Kruschke, J.K. (2015). Doing Bayesian Data Analysis. Amsterdam: Academic Press.

Lindstrom, K. (1992). The effect of resource holding potential, nest size and information about resource quality on the outcome of intruder-owner conflicts in the sand goby. Behavioral Ecology and Sociobiology, 30, 53-58.

McGinley, R.H., Prenter, J. \& Taylor, P.W. (2015). Assessment strategies and decision-making in male-male contests of Servaea incana jumping spiders. Animal Behaviour, 101, 89-95.

Mesterton-Gibbons, M., Marden, J.H. \& Dugatkin, L.A. (1996). On wars of attrition without assessment. Journal of Theoretical Biology, 181, 65-83.

Moore, N.P., Kelly, P.F., Cahill, J.P. \& Hayden, T.J. (1995). Mating strategies and mating success of fallow (Dama dama) bucks in a non-lekking population. Behavioral Ecology and Sociobiology, 36, 91-100.

Noël, M.V., Grant, J.W.A. \& Carrigan, J.G. (2005). Effects of competitor-to-resource ratio on aggression and size variation within groups of convict cichlids. Animal Behaviour, 69, 11571163.

Nosil, P. (2000). Food fights in house crickets, Achetus domesticus, and the effects of body size and hunger level. Canadian Journal of Zoology, 80, 409-417.

Parker, G.A. \& Rubenstein, D.I. (1981). Role assessment, reserve strategy, and acquisition of information in asymmetric animal conflicts. Animal Behaviour, 29, 221-240.

Parker, G.A. (1974). Assessment strategy and evolution of fighting behaviour. Journal of Theoretical Biology, 47, 223-240.

Payne, R.J.H. \& Pagel, M. (1996). Escalation and time costs in displays of endurance. Journal of Theoretical Biology, 183, 156-193.

Payne, R.J.H. \& Pagel, M. (1997). Why do animals repeat displays? Animal Behaviour, 54, 109-119.

Payne, R.J.H. (1998). Gradually escalating fights and displays: the cumulative assessment model. Animal Behaviour, 56, 651-662. 
Riechert, S.E. (1998). Game theory and animal contests. In Game Theory and Animal Behavior (Eds. L.A. Dugatkin and H.K. Reeve), pp. 64-93. Oxford: Oxford University Press.

Rodriguez-Girones, M.A., Drummond, H. \& Kacelnik, A. (1996). Effect of food deprivation on dominance status in blue-footed booby (Sula nebouxii) broods. Behavioral Ecology, 7, 82-88.

Sneddon, L.U., Huntingford, F.A., Taylor, A.C. \& Clare, A.S. (2003). Female sex pheromone-mediated effects on behaviour and consequences of male competition in the shore crab (Carcinus maenas). Journal of Chemical Ecology, 29, 55-70.

Taylor, P.W. \& Elwood, R.W. (2003). The mismeasure of animal contests. Animal Behaviour, 65, 1195-1202. Animal Behaviour, 36, 321-326. 
Figure 1. The mean distribution and $95 \%$ credible intervals examining the relationship between contest behaviour and dominance in relation to mating opportunities at the (a) lower binary and (b) upper truncated Poisson levels of the model.

Figure 2. The relationship between the number of (a) backward pushes and (b) jump clashes made by the subordinate male during the pre-rut and rut.

608

Figure 3. The mean distribution and $95 \%$ credible intervals examining the relationship between contest behaviour and mating success for dominant members of fight dyads at the (a) lower binary and (b) upper truncated Poisson levels of the model.

612

Figure 4. The relationship between the rate of backward pushes and whether the dominant member of the fighting dyad achieved a mating or not on a particular day.

Figure 5. The mean distribution and $95 \%$ credible intervals examining the relationship between contest behaviour and mating success for subordinate members of fight dyads at the (a) lower binary and (b) upper truncated Poisson levels of the model.

Figure 6. The relationship between the number of parallel walks during fights and mating success of subordinate members of the dyad during the rut. 


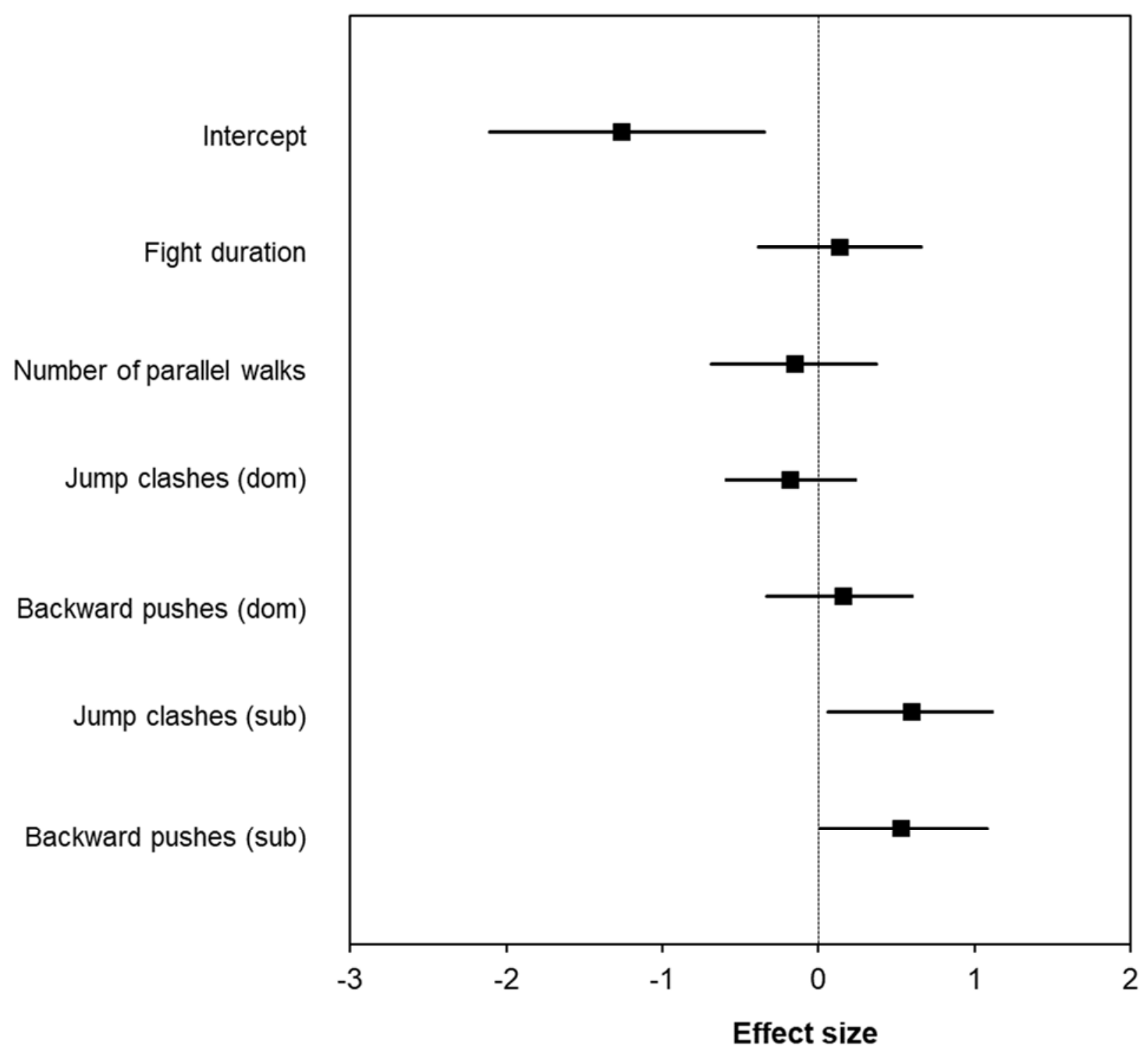




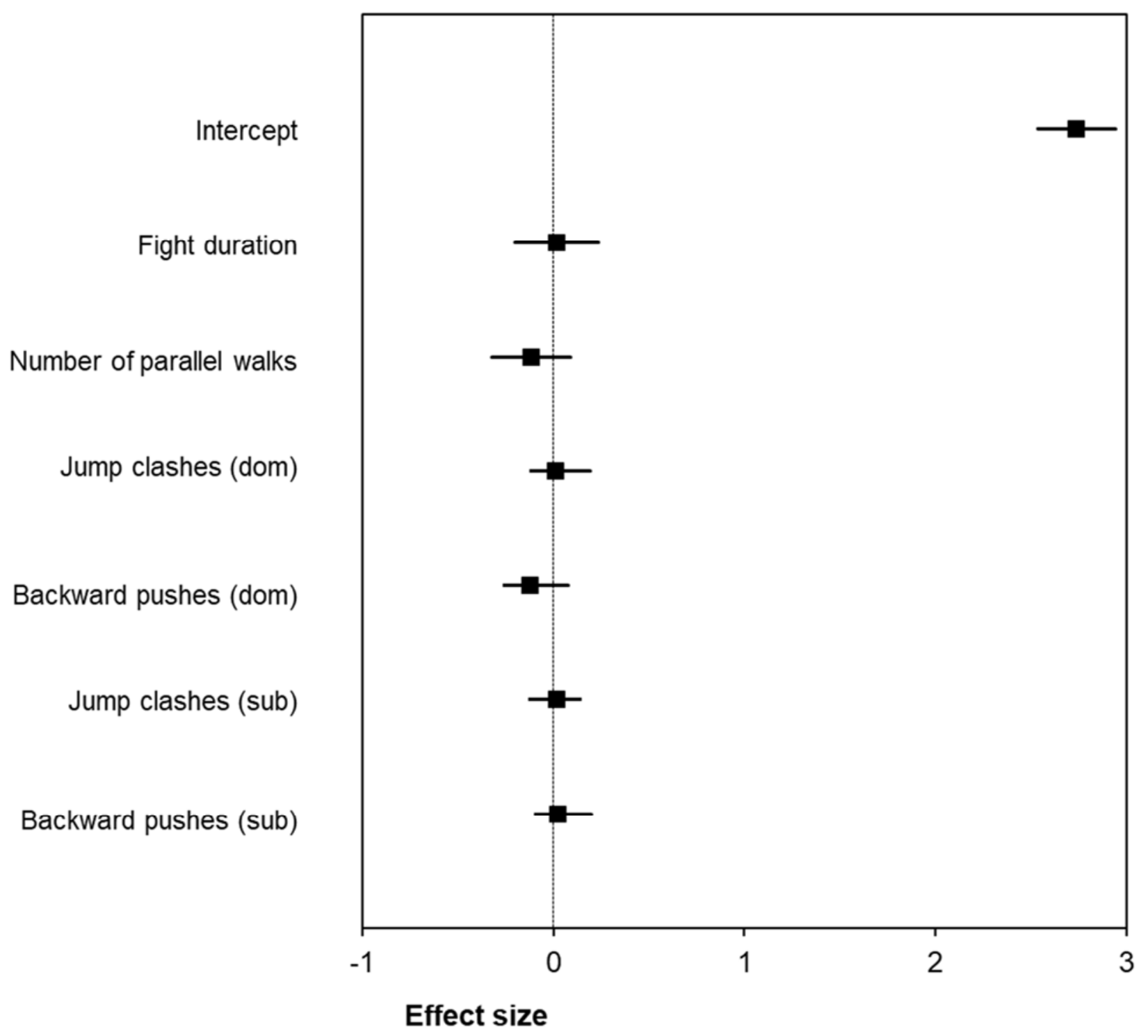

632

633 


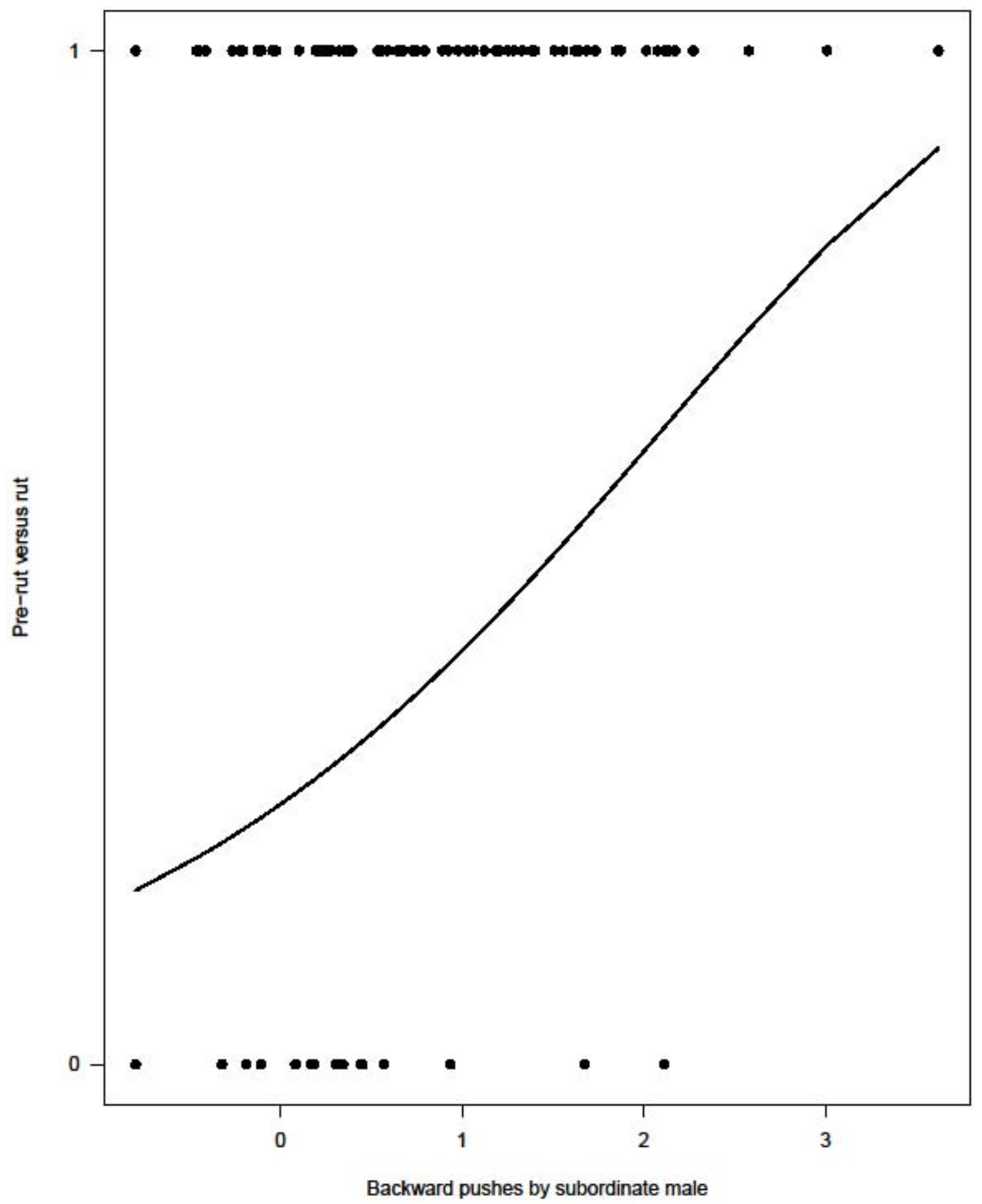




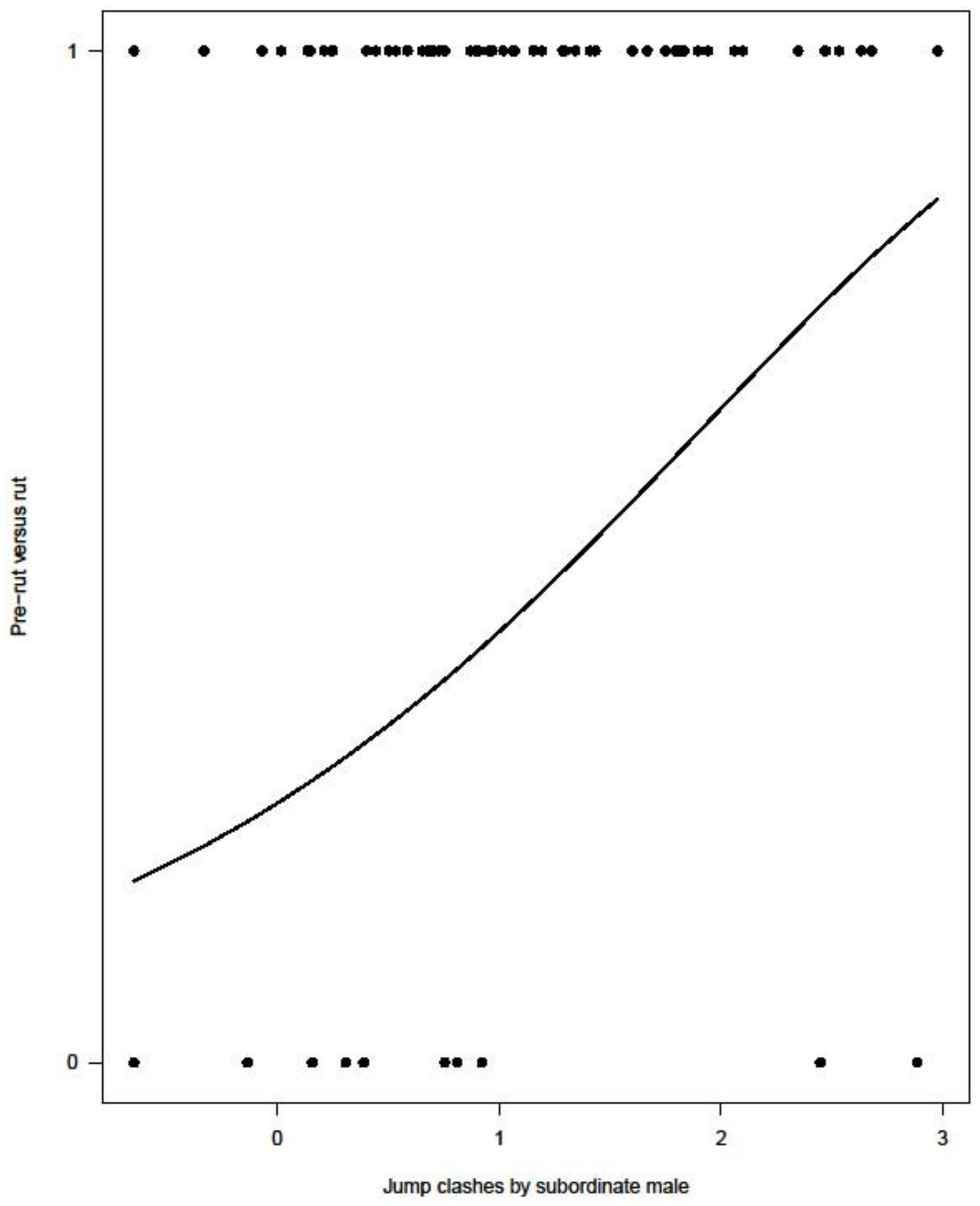




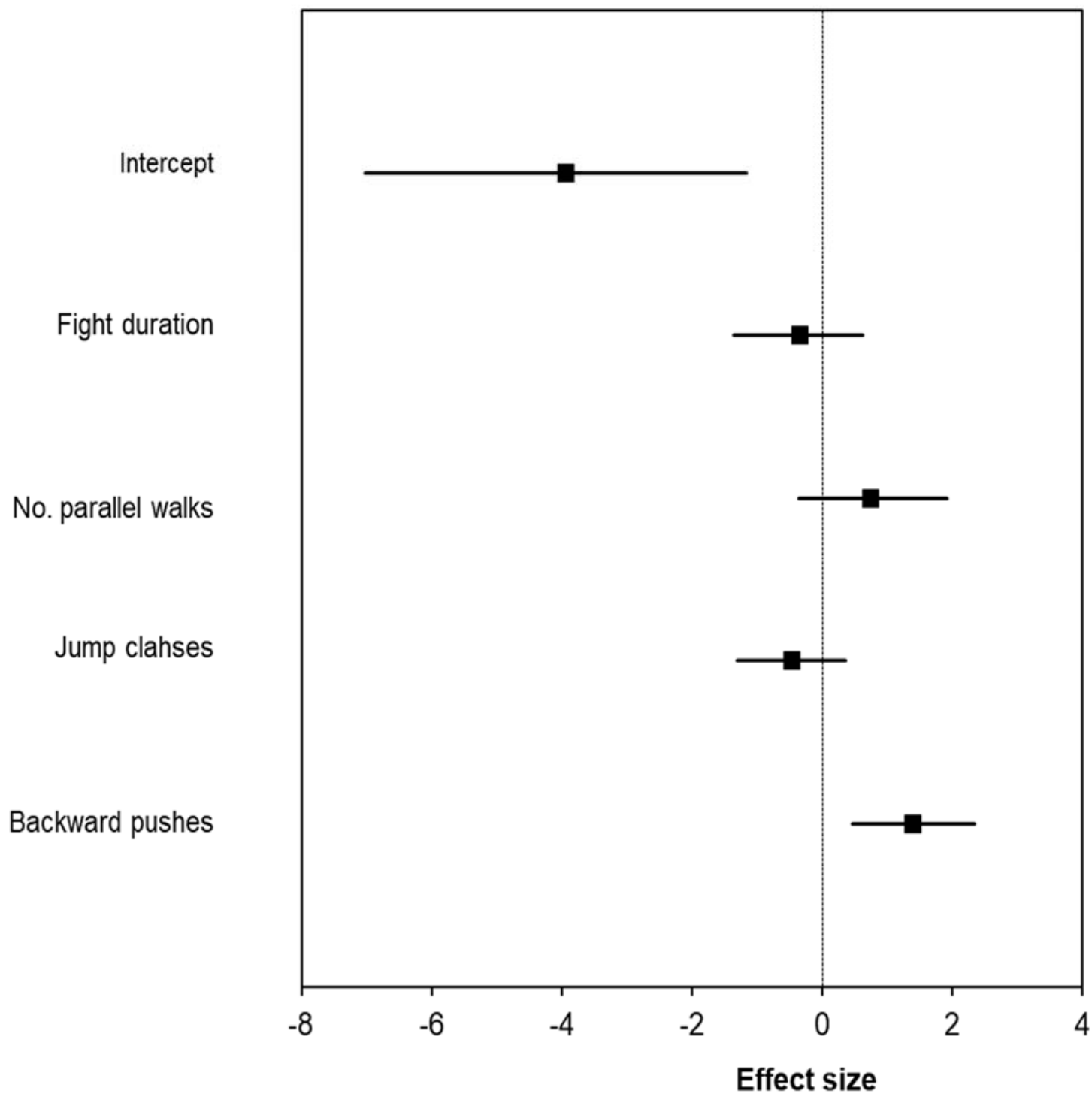


Figure $3 b$

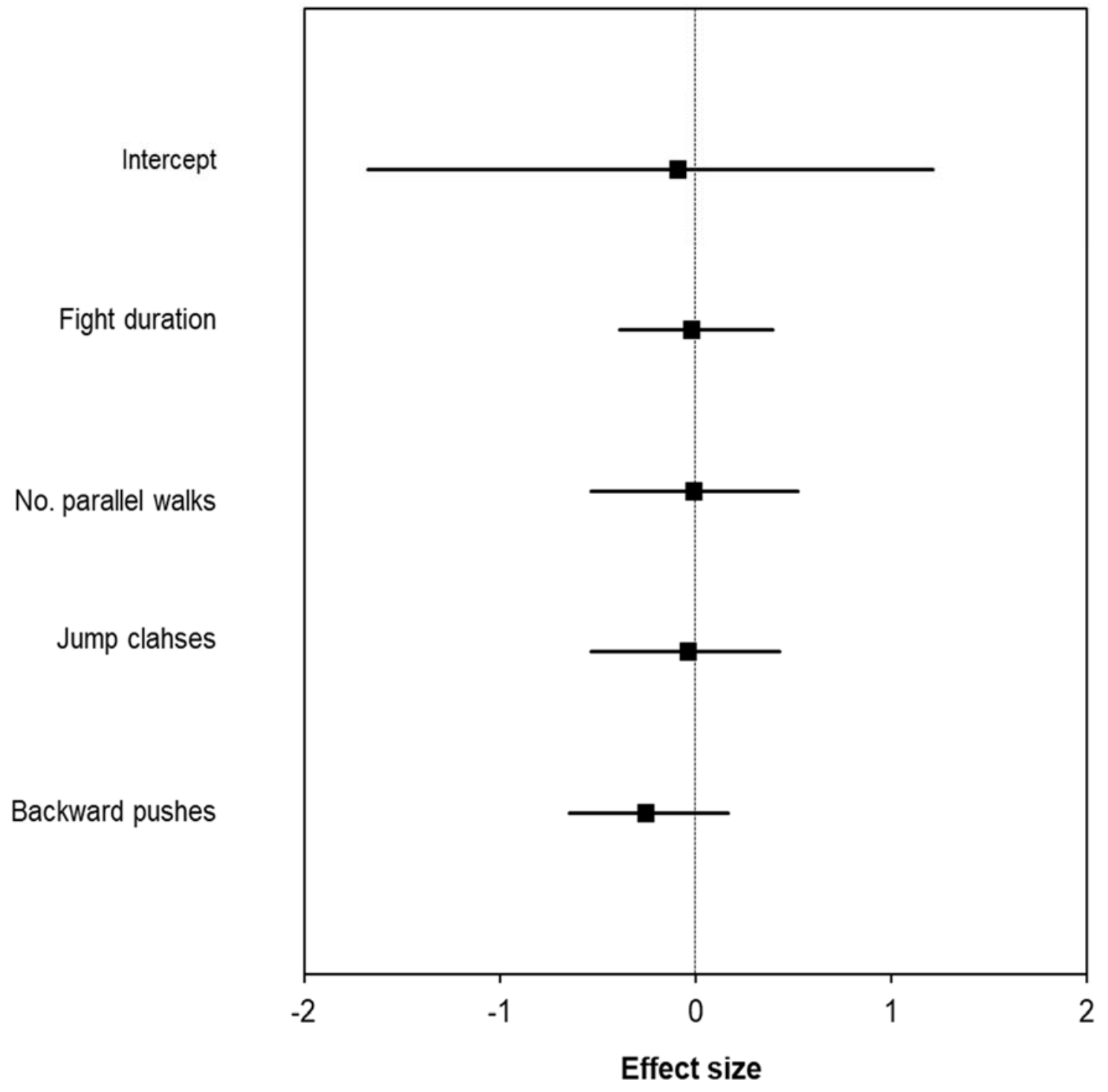

642 


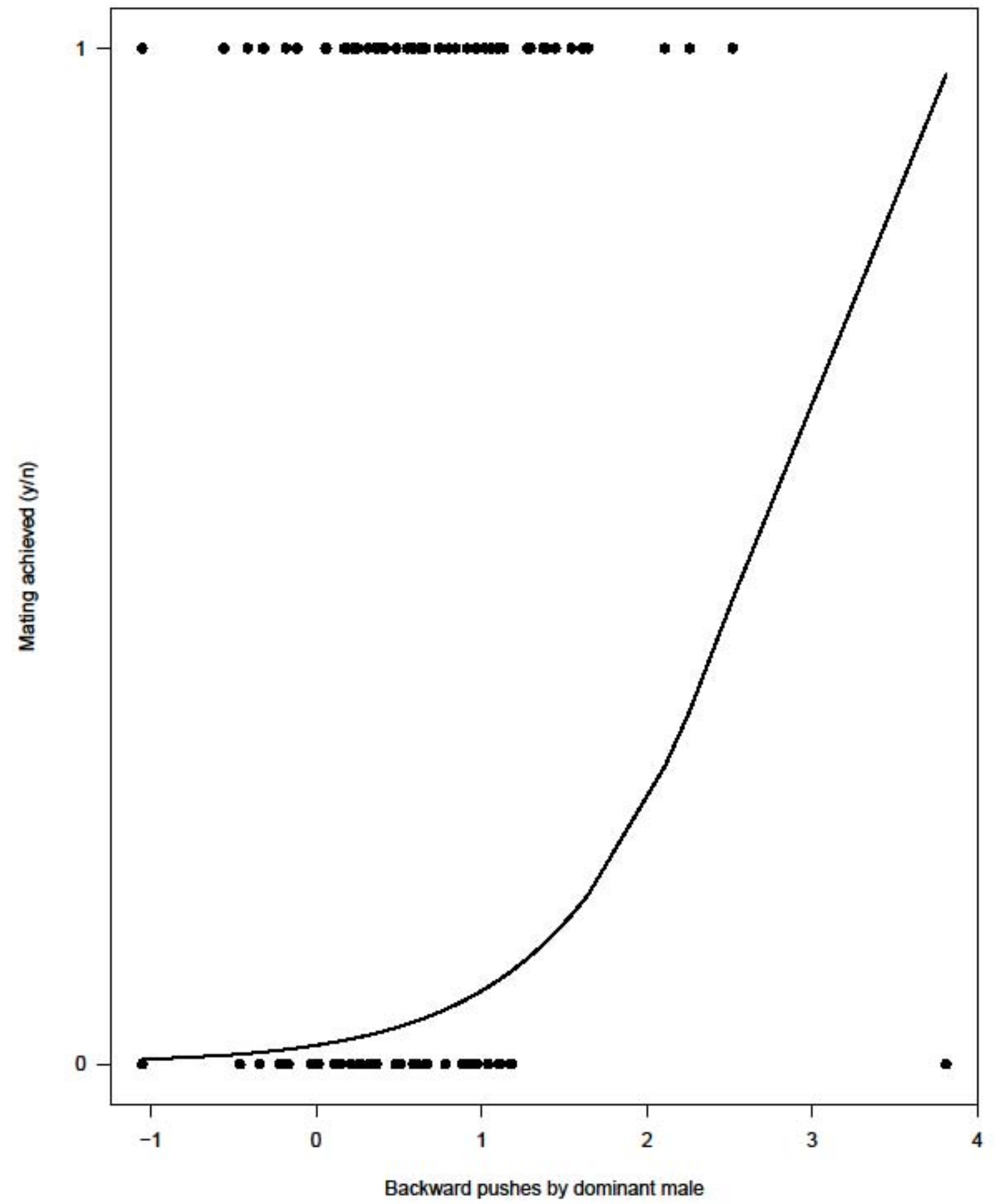

644 


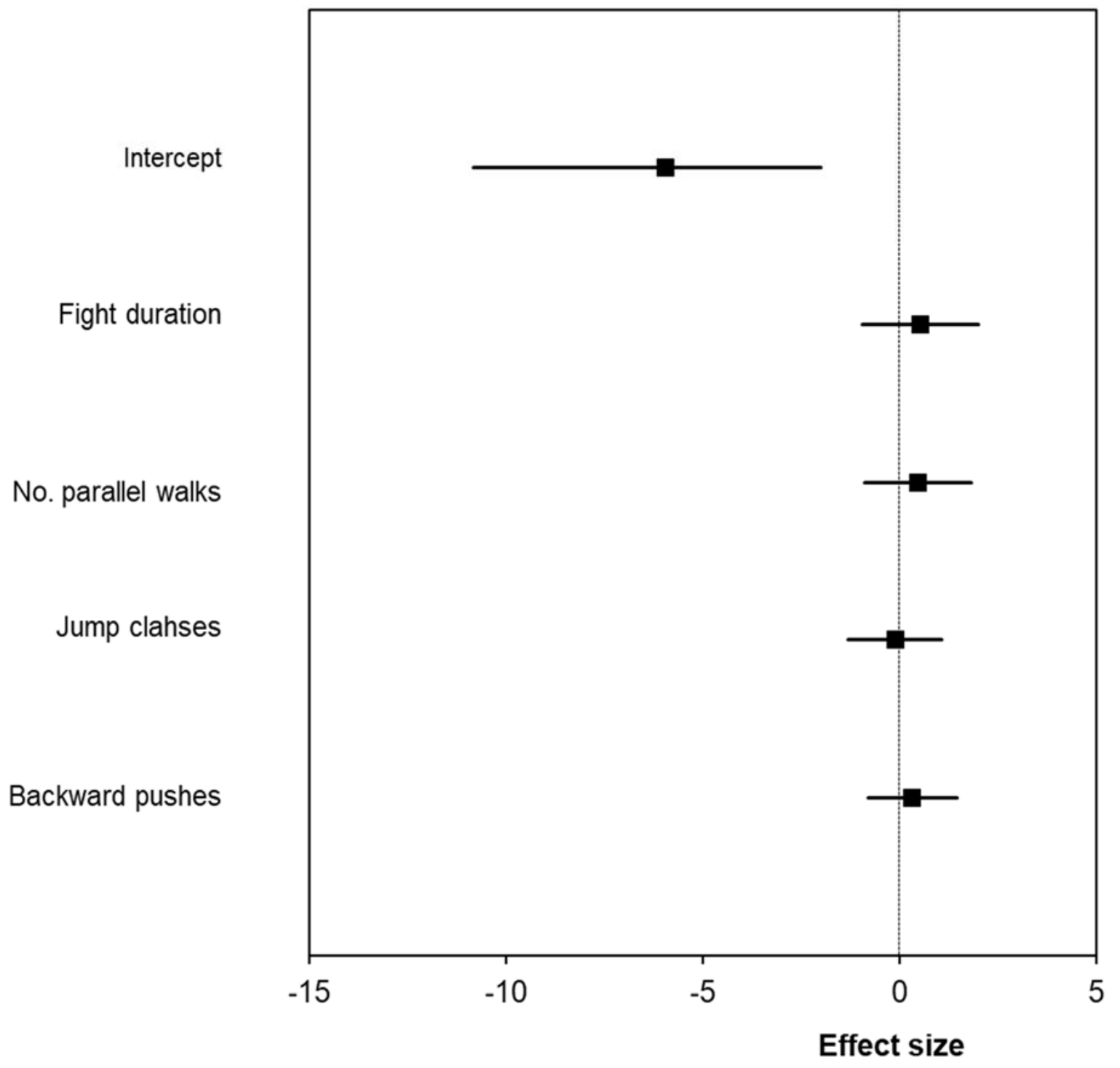

646 


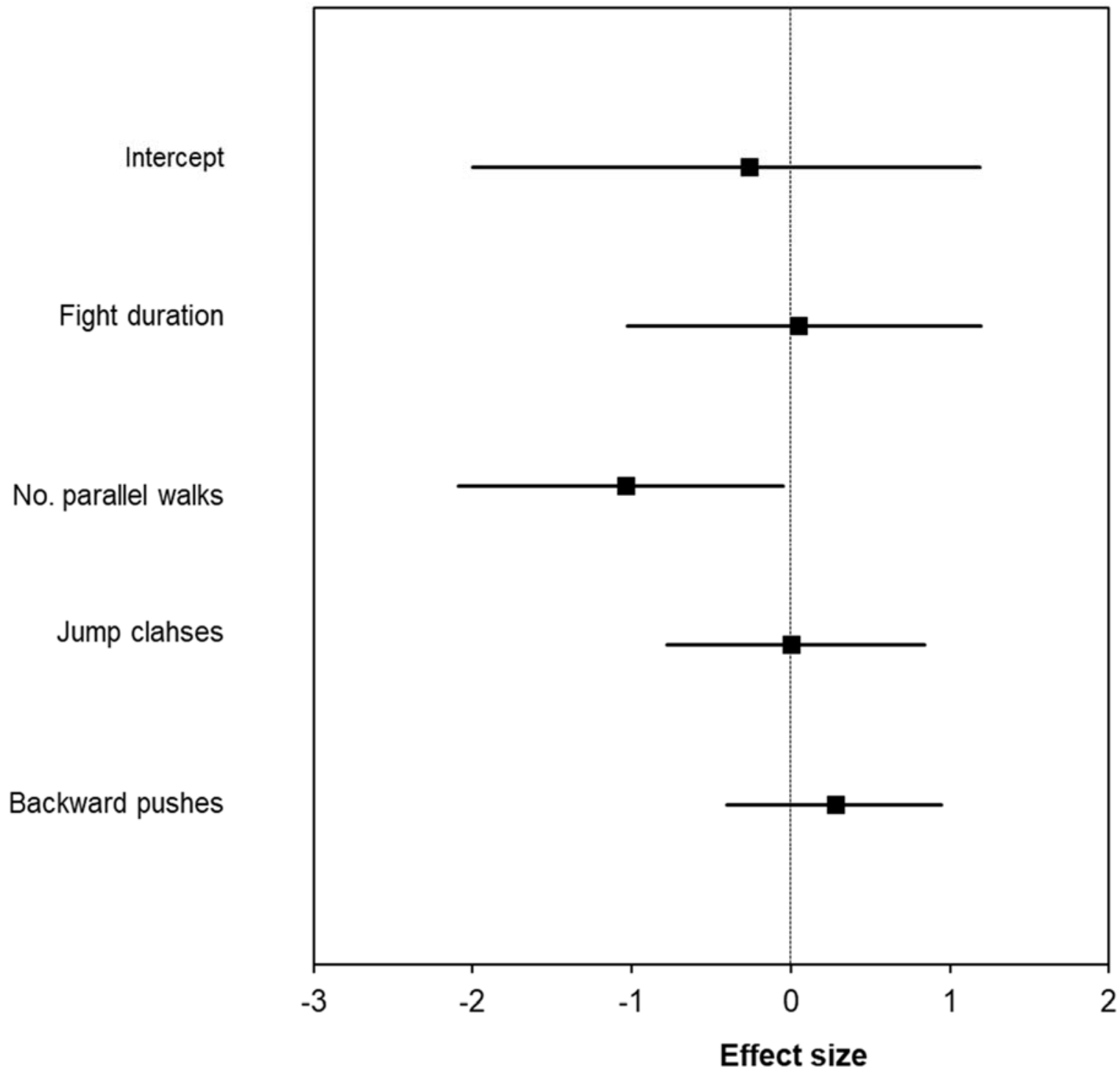


Figure 6

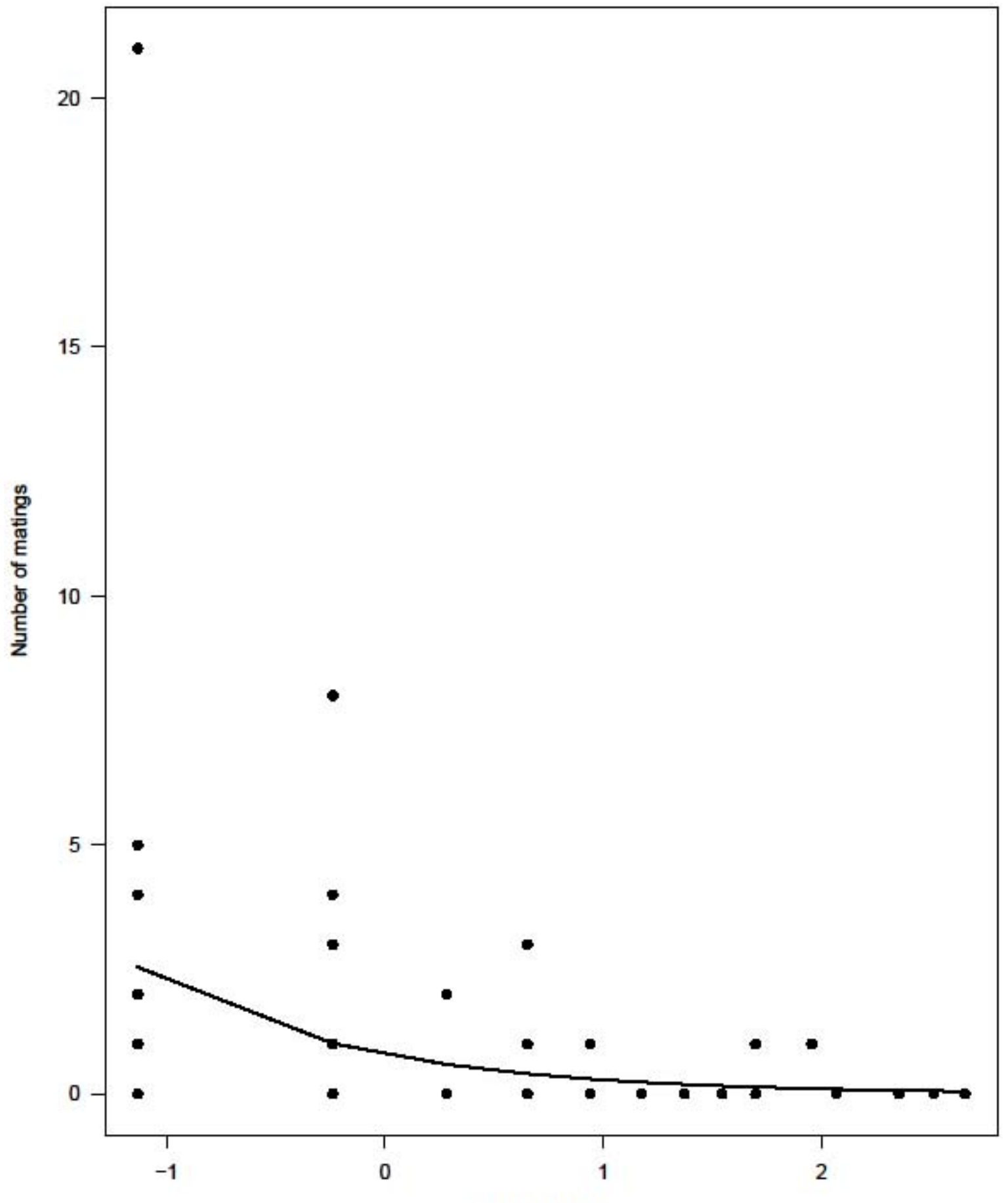

Parallel walks

652 